\title{
A Study on the Adolescent's Perception about Their Family Environment
}

\author{
Dr.Uma Devi.L* Kavitha Kiran.V** \\ *Professor, Dept of Human Development and Family studies, College of Home science, Hyderabad, \\ ** Research associate, Dept of Human Development and Family studies, College of Home science, Hyderabad
}

\begin{abstract}
The present study is an attempt to examine the perceptions of adolescents about their family environment. Two hundred and twenty four adolescents who were in the age range of $15+$ to $18+$ years constituted the sample. Family Environment scale by Bhatia \& Chadda (1996) was used to assess the adolescents perceptions about their family environment. Results of the study revealed that majority of the adolescents studied had average perception about cohesion, expressiveness, acceptance and caring and active recreational orientation dimensions of family environment. Interestingly two thirds of the sample studied scored low on independence dimension. It is surprising to note that adolescent boys and girls did not differ significantly on any dimension of family environment. It is also evident that younger adolescents were more expressive than the older ones. It is interesting to note that adolescents of biological science group were more expressive than other arts groups and mathematics science group students.
\end{abstract}

\section{Introduction}

Adolescent age is period of stress, storm and intense moodiness. Family is the most important support system available to the child. Relationship with parents is an important factor in molding the adolescent personality. Adolescents have a poor reputation of getting along poorly with their families. The teenage boy or girl may be faced with serious problems of adjustment when there is a difference of opinions, ideals and attitudes with their parents. Conflicts may arise between the adolescent and the parents that are difficult to resolve if neither is willing nor able to compromise.

Family cohesion (i.e., the emotional bonding among family members and the feeling of closeness) is expressed by feelings of belonging and acceptance within the family system (McKeown et al., 1997). Wentzel and Feldman (1996) and McKeown et al. have found that adolescent perceptions of low cohesion within their families were associated with heightened feelings of depression and reduced social acceptance. Reinherz,

Stewart-Berghauer, Pakiz, Frost, and Moeykens (1989) suggest that low cohesion, expressed by feelings of not belonging, is associated with children's and adolescents feeling's and behaviour that are reflective of their family environment

\section{Objective}

- To study the perceptions of adolescents on family environment.

- To examine the differences of age, gender and group of study if any on adolescent's perception about family environment

\section{Sample}

\section{Method}

The study was carried out in the twin cities of Hyderabad in Andhra Pradesh. Coeducational institutions with intermediate classes were selected for the purpose of study. The sample comprised of 224 adolescent children in the age range of $15+$ to 18 years.

Tools used :

a) Family back ground information schedule to collect personal profile of the sample.

b) Family environment scale by Bhatia \& Chadda (1996) to assess the perceptions of adolescents on family environment.

\section{Data collection procedure :}

The principals of selected coeducational junior colleges were contacted and permission was taken for data collection. The family environment scale was administered on the selected adolescents. Necessary instructions were given regarding the answering of the test items. Scoring was done according to the instructions given in the manual. 


\section{Statistical analysis used :}

Frequencies and percentages were used to depict the personal profile of the sample and adolescents perception about family environment. ' $Z$ ' test and $F$ ratios were used to study the mean differences in perception of adolescents of different gender, age and group of study on family environment.

\section{Results \& Discussion}

General Profile of the Sample: From the general profile of the respondents it was found that 76 percent of adolescent boys and girls fell into $16+$ and $17+$ years age group followed by $15+$ and $18+$ age group. Regarding class of study $51 \%$ boys and 47 percent girls were studying junior intermediate and the remaining of them were studying senior intermediate. Percentage distribution of adolescents based on group of study revealed that $1 / 3^{\text {rd }}$ of the boys and girls have taken MPC group(mathematics, Chemistry and Physics) followed by $\mathrm{CEC}($ commerce,economics and civics),MEC and Bi.P.C. compared to boys girls were more in Bi.P.C group.

Perceptions of Adolescents on Family environment: Effective family functioning defined by cohesion, expressiveness and high personal growth are related positively to peer relations and role compliance. The more cohesive a family, the better the individual family members to function, the better the communication between parents and children and greater the marital consensus and better the behaviour outcomes for adolescent children(Farell \& Barnes,1993). Table.1 shows the distribution of sample based on adolescents perception about different dimensions of family environment. The data collected on this aspect revealed that adolescents had average perception on dimensions like cohesion, expressiveness, conflicts, acceptance and caring and active recreational orientation dimensions of family environment. This might be due to the fact that as the respondents were from urban nuclear intact families, opportunities for emotional togetherness is more and importance is given to express individual feelings. Because of small nuclear family, children were accepted and cared for by both the parents and opportunities for more recreational activities were provided. In case of independence dimension, 2/3rds of the sample perceived that they has less freedom at home and around 50 percent perceived that they have average organizational capacities at home. These results clearly depict the characteristics of adolescence. As it is a transition period adolescent felt that they were not completely independent because parents neither treat them as children nor grown ups and put them in ambiguous position. The same may be responsible for organization and control dimension also.

Table 1: Distribution of Adolescents Based on their perception on Family Environment

\begin{tabular}{|c|c|c|c|c|c|c|c|}
\hline \multirow[t]{2}{*}{ Sl. No. } & \multirow[t]{2}{*}{ Family Environment Dimensions } & \multicolumn{2}{|c|}{ Boys (112) } & \multicolumn{2}{|c|}{ Girls (112) } & \multicolumn{2}{|c|}{ Total(224) } \\
\hline & & No. & $\%$ & No. & $\%$ & No. & $\%$ \\
\hline \multirow[t]{4}{*}{1} & \multicolumn{7}{|l|}{ Cohesion } \\
\hline & Low & 9 & 8 & 4 & 3 & 13 & 6 \\
\hline & Average & 79 & 71 & 85 & 76 & 164 & 73 \\
\hline & High & 24 & 21 & 23 & 21 & 47 & 21 \\
\hline \multirow[t]{4}{*}{2.} & \multicolumn{7}{|l|}{ Expressiveness } \\
\hline & Low & 9 & 8 & 4 & 3 & 13 & 6 \\
\hline & Average & 79 & 71 & 85 & 76 & 154 & 73 \\
\hline & High & 24 & 21 & 23 & 21 & 47 & 21 \\
\hline \multirow[t]{4}{*}{3.} & \multicolumn{7}{|l|}{ Conflict } \\
\hline & Low & 21 & 19 & 12 & 11 & 33 & 15 \\
\hline & Average & 73 & 65 & 81 & 72 & 154 & 68 \\
\hline & High & 18 & 16 & 19 & 17 & 37 & 17 \\
\hline \multirow[t]{4}{*}{4.} & \multicolumn{7}{|l|}{ Acceptance \& caring } \\
\hline & Low & 18 & 16 & 10 & 9 & 28 & 13 \\
\hline & Average & 85 & 76 & 94 & 84 & 179 & 80 \\
\hline & High & 9 & 8 & 8 & 7 & 17 & 7 \\
\hline \multirow[t]{4}{*}{5.} & \multicolumn{7}{|l|}{ Independence } \\
\hline & Low & 66 & 59 & 66 & 59 & 132 & 60 \\
\hline & Average & 43 & 38 & 46 & 41 & 84 & 39 \\
\hline & High & 3 & 3 & 0 & 0 & 3 & 1 \\
\hline \multirow[t]{4}{*}{6} & \multicolumn{7}{|l|}{ Active recreational Orientation } \\
\hline & Low & 27 & 24 & 23 & 21 & 50 & 23 \\
\hline & Average & 74 & 66 & 81 & 72 & 155 & 69 \\
\hline & High & 11 & 10 & 8 & 7 & 17 & 8 \\
\hline \multirow[t]{4}{*}{7} & \multicolumn{7}{|l|}{ Organization } \\
\hline & Low & 12 & 11 & 20 & 18 & 32 & 14 \\
\hline & Average & 62 & 55 & 65 & 58 & 127 & 57 \\
\hline & High & 38 & 34 & 27 & 24 & 65 & 29 \\
\hline \multirow[t]{4}{*}{8} & \multicolumn{7}{|l|}{ Control } \\
\hline & Low & 22 & 20 & 23 & 21 & 45 & 20 \\
\hline & Average & 55 & 49 & 48 & 43 & 103 & 46 \\
\hline & High & 35 & 31 & 41 & 36 & 76 & 34 \\
\hline
\end{tabular}


Table 2: Mean differences of adolescent boys and girls on perception about family environment.

\begin{tabular}{|l|l|l|l|l|l|l|}
\hline Sl. & Dimensions of Family Environment & \multicolumn{2}{l}{ Boys } & Girls & 'Z' value \\
\cline { 3 - 7 } No. & & Mean & S.D & Mean & S.D & \\
\hline 1. & Cohesion & 53.38 & 10.10 & 55.49 & 7.42 & $1.786 \mathrm{NS}$ \\
\hline 2. & Expressiveness & 32.91 & 7.04 & 33.31 & 6.04 & $0.460 \mathrm{NS}$ \\
\hline 3. & Conflict & 41.68 & 8.74 & 41.83 & 7.47 & $0.132 \mathrm{NS}$ \\
\hline 4. & Acceptance and caring & 45.53 & 9.18 & 45.91 & 6.78 & $0.349 \mathrm{NS}$ \\
\hline 5 & Independence & 28.83 & 6.47 & 28.48 & 4.82 & $0.458 \mathrm{NS}$ \\
\hline 6. & Active recreational orientation & 27.97 & 5.55 & 27.91 & 4.47 & $0.079 \mathrm{NS}$ \\
\hline 7 & Organization & 8.24 & 2.19 & 8.21 & 1.81 & $0.099 \mathrm{NS}$ \\
\hline 8. & Control & 15.32 & 3.71 & 15.75 & 3.26 & $0.920 \mathrm{NS}$ \\
\hline
\end{tabular}

*p>0.05; **p>0.01;NS: not significant

Differences of boys and girls on perception about dimensions of family environment : It is interesting to note from the results (table-2) that the mean values for all eight dimensions of family environment were similar for both boys and girls and did not differ significantly as ' $z$ ' values obtained were very low. Hence, it can be inferred from the results that both adolescent boys and girls had similar perception about different dimensions of their family environment as most of them were from intact families. In contrary, Carpenter and Fleishman(1987), Hussler \& Stage(1992) and Georgiou(1995) reported females surpassing males interms of expressing family cohesion.

Table 3: Mean differences of adolescents of different age groups on perception about family environment.

\begin{tabular}{|c|c|c|c|c|c|c|}
\hline \multirow[t]{2}{*}{ SI. No. } & \multirow[t]{2}{*}{ Dimensions of Family Environment } & \multicolumn{4}{|c|}{ Age in Years } & \multirow[t]{2}{*}{ 'F' value } \\
\hline & & $15+$ & $16+$ & $17+$ & $18+$ & \\
\hline 1. & Cohesion & 54.64 & 54.85 & 54.65 & 52.18 & $1.338 \mathrm{NS}$ \\
\hline 2. & Expressiveness & 33.32 & 33.43 & 31.63 & 25.33 & $2.284 *$ \\
\hline 3. & Conflict & 40.90 & 42.44 & 42.00 & 40.40 & $0.613 \mathrm{NS}$ \\
\hline 4. & Acceptance and caring & 45.16 & 45.94 & 46.07 & 45.00 & $0.229 \mathrm{NS}$ \\
\hline 5 & Independence & 28.51 & 28.95 & 28.53 & 27.95 & $0.286 \mathrm{NS}$ \\
\hline 6. & Active recreational orientation & 28.80 & 28.56 & 27.60 & 25.81 & $0.137 \mathrm{NS}$ \\
\hline 7 & Organization & 8.45 & 8.20 & 8.39 & 7.59 & $1.959 \mathrm{NS}$ \\
\hline 8. & Control & 15.96 & 15.41 & 15.77 & 14.77 & $0.522 \mathrm{NS}$ \\
\hline
\end{tabular}

$* p>0.05 ; * * p>0.01 ; N S:$ not significant

Mean Differences of adolescents of different age groups on perception about dimensions of family environment : Analysis of variance was carried out to see whether there was any significant difference in the perception about family environment of different age groups. It is of interest to note from the results (table-3) that the adolescents of different age groups differed significantly in perception about expressiveness dimension of family environment as the mean scores for different age groups ranged from 25-33. The results clearly indicate that younger adolescents $\left(15+, 16^{+}\right)$had better perception about expressiveness dimension $(33.32,33.43)$ of their families than older adolescents who were in $17+$ and $18+$ years age group $(31.67,25.33)$ and the difference is significant at $5 \%$ level. This might be due to the fact that younger adolescents still consider themselves as children, hence were more free to express their feelings than older adolescents who were in transition period. For the remaining seven dimensions, adolescents of different age groups did exhibit similar perceptions, which is evident through 'F' ratios obtained which are not significant.

Table 4: Mean differences of adolescents of different groups of study on perception about family environment.

\begin{tabular}{|l|l|l|l|l|l|l|}
\hline Sl. No. & Dimensions of Family Environment & Group of study & 'FEC & Bi.PC & MPC & \\
\cline { 3 - 7 } & & CEC & MElue \\
\hline 1. & Cohesion & 53.48 & 54.77 & 55.43 & 54.56 & $0.436 \mathrm{NS}$ \\
\hline 2. & Expressiveness & 31.40 & 34.38 & 34.84 & 32.96 & $3.046^{*}$ \\
\hline 3. & Conflict & 41.16 & 43.25 & 42.51 & 41.01 & $0.934 \mathrm{NS}$ \\
\hline 4. & Acceptance and caring & 45.27 & 45.90 & 45.82 & 45.96 & $0.098 \mathrm{NS}$ \\
\hline 5 & Independence & 28.45 & 29.36 & 29.25 & 28.10 & $0.627 \mathrm{NS}$ \\
\hline 6. & Active-recreational orientation & 27.15 & 28.56 & 28.17 & 28.16 & $0.143 \mathrm{NS}$ \\
\hline 7 & Organization & 8.34 & 8.63 & 8.00 & 8.00 & $1.175 \mathrm{NS}$ \\
\hline 8. & Control & 15.15 & 15.27 & 15.92 & 15.82 & $0.678 \mathrm{NS}$ \\
\hline
\end{tabular}

*p $>0.05 ; * * p>0.01 ; N S$ : not significant

Mean Differences of adolescents of different groups of study on perception about dimensions of family environment : Results on perception of adolescents of different groups of study on different dimensions of family environment are presented in table-4. From the results it is clearly evident that group of study had significant impact on the adolescent's perception about expressiveness dimension of family environment. Adolescents of M.E.C group and Bi.P.C group scored higher than M.P.C and C.E.C group and the difference 
was significant at $5 \%$ level. For the other seven dimensions of family environment, Adolescents of different groups of study did have similar perceptions, hence did not differ significantly.

\section{Conclusion}

From the results of the study it can be concluded that majority of adolescents studied had average perception about their families on dimensions like cohesion, expressiveness, acceptance and caring, active recreational orientation and conflict. Majority of the sample felt that they were given less independence at home. Gender differences were not noticed in the perception of adolescents on all eight dimensions of family environment. However, younger adolescents who were from biological science group were more expressive than older and who were from other three groups of study. The results of the study clearly indicates that there is a need to take measures to improve adolescents perception about three dimensions - organization, control and independence to make them potential individuals of tomorrow.

\section{References}

[1.] Bhatia,H., \& Chadda,N.K.(1996). Family Environmnet Scale, Agra Psychological Corporation,Agra

[2.] Carpenter,P., \& Fleisman,J.(1987). Linking intensions and behaviour.Australian students college plans and college attendance.American Educational Research Journal,24,79-105.

[3.] Farell,M.P.,\& Branes,G.M.(1993family system and social support.A test of the effects of cohesion and adaptability on functioning of parents and adolescents. Journal of marriage \& family,55,119-132.

[4.] Georgiou,S.N.(1995).Family dynamics and school achievement in Cyprus.Journal of Child Psychology and Psychiatry,36(6),977991.

[5.] Hussler,D., \& Stage,F.(1992).Family and high school experience influences in the post secondary educational plans of $9^{\text {th }}$ grade students.American Educational Reseach Journal,29,425-451.

[6.] McKeown, R. E., Garrison, C. Z., Jackson, K. L., Cuffe, S. P., Addy, C. L., \& Waller, J. L. (1997).Family structure and cohesion, and depressive symptoms in adolescents. Journal of Research on Adolescence, 7, 267-282.

[7.] Reinherz, M. Z., Stewart-Berghauer, G., Pakiz, B., Frost, A. K., \& Moeykens, B. A. (1989). The relationship of early risk and current mediators to depressive symptomology in adolescence. Journal of the American Academy of Child and Adolescent Psychiatry, 28, 134-142

[8.] Wentzel, K. R., \& Feldman, S. S. (1996). R elations of cohesion and power in family dyads to social and emotional adjustment during early adolescence. Journal of Research on Adolescences, 2,225-245 